OPEN ACCESS

Edited by:

Gilles Benichou,

Partners HealthCare, USA

Reviewed by:

Amir Ahmed Toor

Virginia Commonwealth

University, USA

Emmanuel Zorn,

Columbia University

Medical Center, USA

*Correspondence:

Jean-Luc Taupin

jean-luc.taupin@aphp.fr

Specialty section:

This article was submitted to Alloimmunity and Transplantation,

a section of the journal

Frontiers in Immunology

Received: 26 April 2016

Accepted: 28 July 2016

Published: 12 August 2016

Citation:

Morin-Zorman S, Loiseau P, Taupin J-L and Caillat-Zucman S (2016) Donor-Specific Anti-HLA

Antibodies in Allogeneic

Hematopoietic Stem Cell

Transplantation.

Front. Immunol. 7:307.

doi: 10.3389/fimmu.2016.00307

\section{Donor-Specific Anti-HLA Antibodies in Allogeneic Hematopoietic Stem Cell Transplantation}

\author{
Sarah Morin-Zorman, Pascale Loiseau, Jean-Luc Taupin* and Sophie Caillat-Zucman \\ Laboratoire d'Immunologie et Histocompatibilité, Hôpital Saint-Louis, Assistance Publique Hôpitaux de Paris (APHP), \\ Université Paris Diderot, Paris, France
}

Allogeneic hematopoietic stem cell transplantation (AHSCT) is a curative treatment for a wide variety of hematological diseases. In 30\% of the cases, a geno-identical donor is available. Any other situation displays some level of human leukocyte antigen (HLA) incompatibility between donor and recipient. Deleterious effects of anti-HLA immunization have long been recognized in solid organ transplant recipients. More recently, anti$H L A$ immunization was shown to increase the risk of primary graft failure (PGF), a severe complication of AHSCT that occurs in 3-4\% of matched unrelated donor transplantation and up to $15 \%$ in cord blood transplantation and T-cell depleted haplo-identical stem cell transplantation. Rates of PGF in patients with DSA were reported to be between 24 and $83 \%$ with the highest rates in haplo-identical and cord blood transplantation recipients. This led to the recommendation of anti-HLA antibody screening to detect donor-specific antibodies (DSA) in recipients prior to AHSCT. In this review, we highlight the role of anti-HLA antibodies in AHSCT and the mechanisms that may lead to PGF in patients with DSA, and discuss current issues in the field. Keywords: donor-specific antibodies, HLA antigens, allogeneic hematopoietic stem cell transplantation, graft
failure, single antigen flow bead assay

\section{INTRODUCTION}

Allogeneic hematopoietic stem cell transplantation (AHSCT) is a life-saving procedure for various hematological and immunological conditions. Nowadays $\sim 30 \%$ of AHSCT procedures are performed with human leukocyte antigen (HLA)-identical siblings. Any other situation displays some level of HLA incompatibility between donor and recipient, even in 10/10 matched unrelated donors where a mismatch for HLA-DPB1 and/or DRB3, B4, or B5 is present in $80 \%$ of the cases. Deleterious effects of anti-HLA immunization have long been recognized in solid organ transplantation (1-3). More recently, anti-HLA immunization was shown to increase the risk of graft failure in AHSCT. For this reason, it is now strongly recommended to screen recipients for anti-HLA donor-specific antibodies (DSA) before AHSCT. In this review, we outline the role of anti-HLA antibodies in AHSCT and discuss current issues in the field.

\section{TECHNIQUES FOR HLA ANTIBODY DETECTION AND IDENTIFICATION}

Complement-dependent lymphocytotoxicity (CDC) tests that were used initially have been widely replaced by bead-based assays, such as the single antigen flow bead (SAFB) assays that are more 
sensitive and resolutive (4). This technique allows antigen-specific and even allele-specific antibodies to be identified, using fluorescent micro-spheres each coated with a unique HLA variant/ allele. Each bead subpopulation has a unique color resulting from the mixture of two fluorochromes, all the beads from the same class being mixed together in a multiplex approach. Currently, a panel of nearly 100 class I alleles and quite as many for class II, can be analyzed with minute serum amounts in less than $2 \mathrm{~h}$. Serum is incubated with the beads, unbound serum components are removed through washing, and a phycoerythrin-labeled antihuman IgG is added to identify the HLA alleles recognized by serum antibodies thanks to bead fluorescent coding. Reactivity is measured by Luminex-based technology, using a software program for subtracting background fluorescence of a negative control serum, and is reported as a mean fluorescence intensity (MFI) value. This technique is much more sensitive than the CDC approach, and slightly more than the classical cell-based flow cytometry assay. It, therefore, allows very weak antibodies to be identified, which were not detectable before. This method measures antibody strength, resulting from the concentration of the antibody in the serum combined with antibody affinity/ avidity for the antigen. After nearly 10 years of use, it is still not clear in organ transplantation what the clinically relevant threshold is, as a deleterious clinical impact has been reported at very low MFI (in the 500 range) for kidney transplantation (5). This technique has other limitations, besides its high costs: false-positive reactions possibly caused by co-purified irrelevant antigens, or high level of background reactivity in some patients. Another potential issue is complement interference, the so-called "prozone" effect, that is due to downstream C4- and C3-derived complement activation products that mask the recognition site of the PE-labeled anti-human IgG conjugate and impairs its binding. This can lead to underestimating anti-HLA antibody strength, especially for the strongest ones that would need to be at least detected, if not correctly estimated through their MFI levels. This phenomenon is avoided by preventing complement activation though pre-treatment of serum with EDTA, DTT, or heat, which knock down the complement classical pathway at the initial step involving the calcium-dependent $\mathrm{C} 1$ complex. Despite these downsides, SAFB assays have revolutionized the field, by allowing the precise identification of antigenic targets for anti-HLA antibodies, a goal that could not be technically reached before their advent.

\section{ORIGIN AND PREVALENCE OF ANTI-HLA ANTIBODIES}

"Natural" anti-HLA antibodies can exist in healthy, non-transplanted, non-transfused, non-parous individuals, at a prevalence estimated to be between $<1$ and $5 \%(6,7)$. Some "natural" antibodies are reactive against denatured or cryptic HLA epitopes that are normally hidden in the well-conformed native molecule, whereas others are reactive against native epitopes. Natural antibodies are considered as resulting from cross-reactions with common environmental antigens encountered by individuals all along their lives. Antibodies reactive against denatured epitopes interact with HLA molecules that are ill-configured because of natural instability or due to procedures used to produce, isolate, and adsorb the antigen on the beads (8). Of note, some studies reported on a much higher rate of this kind of allo-immunization, reaching up to $63 \%$ in non-parous individuals (9). This discrepancy may be explained by different techniques used in these studies and/or variable cutoff values for positivity or different bead engineering (10).

Besides natural antibodies, main causes of anti-HLA antibody development are pregnancy, blood product transfusion, and previous transplantation. The incidence of anti-HLA immunization through platelet transfusion was strongly decreased by leukocyte depletion of blood products: in a large trial, it plummeted from $45 \%$ in controls to $17 \%$ in non-parous patients who received leukocyte-depleted platelets (11). However, leukocyte reduction did not solve the issue of allo-immunization related to red blood cell transfusion. The rate of allo-immunization in transfused non-parous individuals who received leukocyte-depleted red blood cells was not reduced in three randomized control trials (12-14): the allo-immunization rate ranged from $10 \%$ in low-risk patients to over $50 \%$ in females with prior pregnancy. In patients suffering from hematological diseases, anti-HLA immunization ranges from 19.6 to $39.4 \%$ (Table 1 ).

\section{IMMUNIZATION AGAINST DONOR HLA MOLECULES IS ASSOCIATED WITH PRIMARY GRAFT FAILURE IN AHSCT}

Studies in the early 2000s associated detection of complementfixing antidonor antibodies in the recipient by cross-match test with an increased risk of AHSCT graft failure $(15,16)$. Although

TABLE 1 | Studies of DSA impact in different settings in AHSCT.

\begin{tabular}{|c|c|c|c|c|c|c|}
\hline Reference & Patients $(n)$ & Stem cell source & Conditioning & Anti-HLA \% & DSA \% & Graft failure with/without DSA \\
\hline Spellman et al. (34) & 115 & Mismatched unrelated & $\mathrm{RIC}$ & ND & 9 & 24 versus $1 \%$ \\
\hline Ciurea et al. (36) & 592 & $10 / 10$ and $9 / 10$ unrelated & MACorRIC & 19.6 & 1.4 & 37.5 versus $2.7 \%$ \\
\hline Yoshihara et al. (39) & 79 & Haplo-identical & $\mathrm{RIC}$ & 20.2 & 14 & 27 versus 3\% \\
\hline Ciurea et al. (36) & 24 & Haplo-identical & $\mathrm{RIC}$ & ND & 21 & 60 versus $5 \%$ \\
\hline Chang et al. (40) & 345 & Haplo-identical & MAC & 25.2 & 11.3 & $61 \%\left(\mathrm{MFl}_{>} 10,000\right)$ versus $3.2 \%$ \\
\hline Ciurea et al. (36) & 122 & Haplo-identical & Non-specified & ND & 18 & 32 versus $4 \%$ \\
\hline Takanashi et al. (41) & 386 & Single CBU & MAC & 23.1 & 5 & 83 versus 32\% \\
\hline Cutler et al. (42) & 73 & Double CBU & MACorRIC & ND & 24 & 57 versus $5.5 \%$ \\
\hline Ruggeri et al. (43) & 294 & Single and double CBU & $\mathrm{RIC}$ & 23 & 5 & 81 versus $44 \%$ \\
\hline Yamamoto et al. (44) & 175 & Single CBU & MACorRIC & 39.4 & ND & $\begin{array}{l}50 \% \text { if anti-HLA-C, DP, DQ, } \\
\text { DRB1/2/3 versus } 16 \%\end{array}$ \\
\hline
\end{tabular}


one case report mentioned the occurrence of graft failure related to post-transplantation DSA acquisition (17), pre-transplant DSA but not de novo post-transplantation DSA have been correlated to primary graft failure (PGF). PGF includes graft rejection, defined by the inability to achieve a neutrophil count of $0.5 \mathrm{~g} / \mathrm{l}$ for three consecutive days at day 28 post transplantation in the absence of donor hematopoiesis. It also includes poor graft function that is a failure to achieve adequate blood counts (neutrophils $>0.5 \mathrm{~g} / \mathrm{l}$, hemoglobin $>8 \mathrm{~g} / \mathrm{dl}$ or platelets $>20 \mathrm{~g} / \mathrm{l}$ ) for three consecutive days in the presence of complete donor hematopoiesis $(18,19)$. PGF is a severe complication occurring in 3-4\% of matched unrelated donor transplantation and in up to $15 \%$ of cord blood and T-cell depleted haplo-identical AHSCT $(20,21)$. This complication considerably increases the early non-relapse mortality after allogeneic stem cell transplantation (22-25). The mechanisms are little known since only few studies have addressed them.

\section{MECHANISMS OF GRAFT FAILURE IN AHSCT}

Mechanisms of alloantibody generation and effector functions have been well studied in solid organ transplantation (26). Studies that investigated the mechanisms of AHSCT graft rejection in murine models showed the dominance of humoral immunity in major histocompatibility complex (MHC) allosensitized mice. Passive transfer of serum from sensitized mice was sufficient to induce rejection in naïve recipients (27). Other authors showed that antibody-mediated rejection in primed recipients was far more rapid than T-cell-mediated rejection in non-primed recipients (28). Importantly, this study suggested that antibodydependent cell-mediated cytotoxicity (ADCC) was the primary mechanism of rejection: allosensitized $\mathrm{FCGR}^{-1-}$ recipients did not reject their grafts. In human, complement activation has long been known in donor-sensitized patients in solid organ transplantation, through the historic complement-dependent cytotoxicity cross match and the deposited C4d staining in biopsies that are hallmarks of humoral rejection, and more recently through the negative impact of C1q binding (29) or C3d binding (30) DSA in SAFB assays. Whether it also represents a significant mechanism of rejection in AHSCT remains unclear. However, recently, a study showed that patients with C1q-binding DSA pre-existing before AHSCT were at higher risk for PGF (31).

The consequence on hematopoietic stem cells was demonstrated in vitro: CD34 + stem cells incubated in the presence of complement and anti-class I or anti-HLA-DR, but not anti-HLADQ antibodies, were not capable of differentiating into lineage producing colonies (32). Anti-HLA-DP antibodies were shown in another study to have a modest (30\%) effect on human myeloid, erythroid or multipotential progenitors but no direct impact on CD34 + cells was demonstrated (33).

\section{IMPACT OF DSA IN DISTINCT HEMATOPOIETIC STEM CELL TRANSPLANTATION SETTINGS}

Approximately $30 \%$ of patients in need for AHSCT have a HLA geno-identical donor. If not, transplantation is performed with
HLA-compatible unrelated donors, or alternative sources of hematopoietic stem cells, such as HLA-incompatible unrelated donors, cord blood, and, increasingly, haplo-identical donors. Table 1 shows the frequency of pre-transplant anti-HLA and DSA in AHSCT recipients, and the consequences on graft failure, according to the stem cell source.

\section{Impact of DSA in the Matched Unrelated Donor Setting}

In the matched unrelated donor setting in Europe, HLA typing is performed for $\mathrm{A}, \mathrm{B}, \mathrm{C}, \mathrm{DRB} 1$, and $\mathrm{DQB} 1$ loci and a $10 / 10$ or at least $9 / 10$ match is sought for. By contrast, in the US, DQB1 typing is not required, and a compatibility of $8 / 8$ is considered as sufficient. In both continents, HLA-DPB1 matching is not required.

In one early study on 60 patients undergoing one-mismatch intra-familial transplantation or unrelated donor transplantation, the presence of anti-HLA antibodies detected by serum crossmatch technique was associated with a significantly increased risk of graft failure when the cross-match test was positive (16). In another study, the authors retrospectively studied 115 patients who had received myeloablative conditioning (MAC) with at least one mismatch among A, B, C, DRB1, DQB1, or DPB1 loci (34). When comparing the frequency of pre-graft DSA in the no-engraftment group versus the engraftment group, they found that $24 \%$ of patients who did not engraft had DSA pre-transplant versus $1 \%$ in patients who did engraft.

To date, the importance of anti-HLA-DPB1 immunization is still debated, especially since DPB1 compatibility is not considered when allocating transplants. As a consequence, $80 \%$ of transplants are performed across a HLA-DPB1 mismatch (35). In a prospective study, the authors studied 592 recipients of unrelated transplants ( $85 \%$ of $10 / 10$ and $16 \%$ of $9 / 10$ matched transplants) who received MAC. DSA were present in $1.4 \%$ of patients, all directed against HLA-DPB1. Graft failure occurred in $3.2 \%$ of cases. This event occurred in $2.7 \%$ of patients without DSA compared with $37 \%$ of patients with DSA (36). Very little is known about the impact of DP expression levels on hematopoietic stem cells on risk of PGF. Interestingly, in this study, HLA DP expression was significantly lower on $\mathrm{CD} 34^{+}$from peripheral blood than from BM, suggesting that risk of PGF might be less important when grafts are obtained from peripheral blood. However, in a retrospective study on 2716 patients who received matched unrelated and mismatched unrelated AHSCT, the engraftment rate was not different in patients receiving stem cells from BM versus peripheral blood (3.7 and 3.9\% of graft failure, respectively, $p=0.83$ ) (37).

\section{Impact of DSA in the Haplo-Identical Transplantation Setting}

In haplo-identical transplantation, only one gene for each locus is matched between donor and recipient. This procedure is undergoing a rapid development because it offers the possibility of having a donor for AHSCT to nearly every patient. Thus, it was crucial to investigate the impact of DSA in this setting. In a retrospective case-control study, which included 24 
patients who received T-depleted haplo-identical transplantation with reduced intensity conditioning (RIC), the incidence of pre-transplant DSA was $21 \%$. Risk of graft rejection was increased from $5 \%$ in the non-DSA group to $60 \%$ in the group with DSA (38). More recent studies were done in T-cell replete haplo-identical transplantation settings. The authors reported that among 79 patients transplanted with RIC, 14\% had DSA, and graft failure was reported in $27 \%$ among them versus $3 \%$ in the no DSA group (39). Larger studies confirmed that the presence of DSA was associated with PGF. In a study on 345 patients with MAC conditioning, $11.3 \%$ had DSA and presence of DSA was associated with PGF in multivariate analysis (40). In a study on 122 patients, $18 \%$ of patients had DSA before transplantation and among them, 7 (32\%) experienced graft failure (31).

\section{Impact of DSA in the Umbilical Cord Blood Transplantation Setting}

In this setting, only HLA-A, -B, and -DRB1 matching is searched for, but not absolutely required. An effect on graft rejection of antibodies against these antigens when mismatched was found in a study on 386 adult patients with MAC conditioning. Importantly, this study was done with single cord blood unit (CBU), which on its own probably partly explains the high rates of graft failure (83\% in group with DSA versus 32\% in group without DSA) (41). In a study on 73 patients who received double CBU with mostly RIC conditioning, PGF occurred in $18 \%$ of patients who had DSA against one CBU and in $57 \%$ of patients who had DSA against both CBU versus only 5.5\% in the no DSA group (42). In another study performed on 294 patients with RIC who received one or $2 \mathrm{CBU}$, engraftment rate at day 60 was 81 versus $44 \%$ in the no DSA group and TRM was also increased from 32 to $43 \%$ in patients with DSA (43). The impact of DSA against HLA-C, -DP, -DQ, and -DR3/4/5 was specifically investigated in another study on 175 patients receiving single $\mathrm{CBU}$, showing that engraftment rate was inferior in HLA-mismatched patients who had anti-HLA antibodies against HLA-C, -DP, DQ, and -DRB3/4/5 compared to patients without anti-HLA antibodies or to patients who had antibodies against HLA-A, -B, or -DRB1 but no DSA. Because typing of HLA-C, -DP, -DQ, and -DRB3/4/5 loci was lacking, the authors hypothesized that unrecognized DSA were responsible for the lower engraftment rates (44).

\section{IMPACT OF DSA MFI STRENGTH}

Several studies have shown that higher MFI of DSA were associated with an increased rate of graft failure (36, 38-40, $42,43)$. However, there is no consensus on a clear cut-off above which the DSA is likely to cause graft failure. In a study, the authors suggested the clinically significant cut-off could be the positivity of the SAFB C1q assay (31), which is grossly correlated with antibody MFI strength in the IgG assay setting, in the field of organ transplant recipients (45-48). However, larger studies are needed to better determine a clear cut-off value.

\section{ROLE OF DONOR-DERIVED HLA ANTIBODIES IN AHSCT RECIPIENTS}

Very little is known regarding the role of donor-derived antiHLA antibodies. Donor-derived antibodies might emerge in recipients of AHSCT because the graft contains memory B cells that can differentiate into plasma cells that could be specific for a given recipient HLA determinant. One study reported the frequent detection of anti-HLA antibodies in patients who underwent AHSCT from anti-HLA antibody-positive donors (49). One group screened 127 donors for anti-HLA antibodies. Seven donors were anti-HLA antibody positive. Among the seven patients who received AHSCT from these donors, four subsequently became anti-HLA antibody positive, with antibodies that closely resembled the antibodies found in their donors. The antibodies had MFI that peaked between Days 20 and 30 in all patients, then decreased and disappeared before Day 100 (50). In a case report about two patients who received haplo-identical transplantation from anti-HLA antibody donors, the recipients became anti-HLA antibody positive and stayed positive for less than a year (51). In these studies, the antibodies were not recipient specific. The impact of recipient-specific compared to non-recipient-specific antibodies is not known. In a recent study, the authors studied a cohort of 82 HLA class II mismatched unrelated AHSCT donor-recipient pairs (52). In this cohort, 26 donors (32\%) had at least one anti-HLA class II antibody detected in peripheral blood. The recipients of a graft from an anti-class II immunized donor had a significantly higher 2 -year cumulative incidence of a first episode of either acute or chronic graft-versus-host disease (88 versus $67 \%$ ), suggesting that donor immunization against foreign HLA antigens could be a new parameter to consider for predicting the risk of GVHD after HLA-mismatched unrelated HSCT. However, this observation needs to be confirmed on a larger cohort and the impact of recipient-specific antibodies to be studied.

\section{STRATEGIES FOR DSA REDUCTION BEFORE TRANSPLANTATION}

The most widely used strategy in case of pre-transplant DSA is to identify and select another donor. Since this is not always possible, several reports mentioned successful strategies to reduce plasma DSA strength prior to transplantation. These reports most often describe single patients or very small series and are possibly biased since failure to reduce DSA might have remained unreported in many cases. The most frequent strategy involved B-lymphocyte depletion with rituximab and plasma exchanges $(38,39)$ sometimes combined with highdose intravenous immune globulins or infusion of irradiated donor lymphocytes (31). The reduction of DSA with these treatments was variable but often only partially effective, treatment efficacy being likely related to pre-existing DSA levels. Another strategy involved transfusion of platelets bearing HLA antigens corresponding to DSA, which induced rapid and significant DSA reduction $(39,53)$. This strategy could be associated with rituximab in order to reduce DSA-producing 
B-lymphocytes (53). Lastly, bortezomib associated with dexamethasone was tested in one patient with a moderate DSA reduction (39).

There is no consensus regarding the appropriate titer at which a strategy of antibody reduction should be applied in HSCT, as there is no consensus on the clinically relevant threshold for DSA strength. There is no consensus in organ transplantation either, but recent reports strongly suggest that DSA clinical impact occur earlier as its serum strength increases at time of transplantation $(29,47)$ In the AHSCT setting, the situation is different, because as soon as complete donor chimerism is reached, DSA production by recipient B cells disappears. For this reason, the threshold for DSA levels that might require therapeutic intervention could be different between both settings.

\section{REFERENCES}

1. Patel R, Terasaki PI. Significance of the positive crossmatch test in kidney transplantation. N Engl J Med (1969) 280(14):735-9. doi:10.1056/ NEJM196904032801401

2. Terasaki PI, Ozawa M. Predicting kidney graft failure by HLA antibodies: a prospective trial. Am J Transplant (2004) 4(3):438-43. doi:10.1111/j.16006143.2004.00360.x

3. Hourmant M, Cesbron-Gautier A, Terasaki PI, Mizutani K, Moreau A, Meurette A, et al. Frequency and clinical implications of development of donor-specific and non-donor-specific HLA antibodies after kidney transplantation. J Am Soc Nephrol (2005) 16(9):2804-12. doi:10.1681/ASN. 2004121130

4. Konvalinka A, Tinckam K. Utility of HLA antibody testing in kidney transplantation. J Am Soc Nephrol (2015) 26(7):1489-502. doi:10.1681/ASN. 2014080837

5. Lefaucheur C, Loupy A, Hill GS, Andrade J, Nochy D, Antoine C, et al. Preexisting donor-specific HLA antibodies predict outcome in kidney transplantation. J Am Soc Nephrol (2010) 21(8):1398-406. doi:10.1681/ASN. 2009101065

6. Endres RO, Kleinman SH, Carrick DM, Steele WR, Wright DJ, Norris PJ, et al. Identification of specificities of antibodies against human leukocyte antigens in blood donors. Transfusion (2010) 50(8):1749-60. doi:10.1111/j.15372995.2010.02589.x

7. Middelburg RA, Porcelijn L, Lardy N, Briët E, Vrielink H. Prevalence of leucocyte antibodies in the Dutch donor population. Vox Sang (2011) 100(3):327-35. doi:10.1111/j.1423-0410.2010.01420.x

8. Zoet YM, Brand-Schaaf SH, Roelen DL, Mulder A, Claas FHJ, Doxiadis IIN. Challenging the golden standard in defining donor-specific antibodies: does the solid phase assay meet the expectations? Tissue Antigens (2011) 77(3):225-8. doi:10.1111/j.1399-0039.2010.01608.x

9. Morales-Buenrostro LE, Terasaki PI, Marino-Vázquez LA, Lee J-H, El-Awar N, Alberú J. "Natural" human leukocyte antigen antibodies found in nonalloimmunized healthy males. Transplantation (2008) 86(8):1111-5. doi:10.1097/TP.0b013e318186d87b

10. Brand A, Doxiadis IN, Roelen DL. On the role of HLA antibodies in hematopoietic stem cell transplantation. Tissue Antigens (2013) 81(1):1-11. doi:10.1111/tan. 12040

11. McFarland J, Menitove J, Kagen L, Braine H, Kickler T, Ness P, et al. Leukocyte reduction and ultraviolet $\mathrm{B}$ irradiation of platelets to prevent alloimmunization and refractoriness to platelet transfusions. The trial to reduce alloimmunization to platelets study group. N Engl J Med (1997) 337(26):1861-9. doi:10.1056/NEJM199712253372601

12. van de Watering L, Hermans J, Witvliet M, Versteegh M, Brand A. HLA and RBC immunization after filtered and buffy coat-depleted blood transfusion in cardiac surgery: a randomized controlled trial. Transfusion (2003) 43(6):765-71. doi:10.1046/j.1537-2995.2003.00390.x

13. Ohto H, Nomizu T, Kuroda F, Hoshi T, Rokkaku Y. HLA alloimmunization of surgical patients by transfusion with bedside leukoreduced blood
In conclusion, although the mechanisms underlying the association between anti-HLA DSA and graft rejection in AHSCT are unclear, numerous studies report on a deleterious effect of DSA on AHSCT engraftment, without clearly identifying innocuous HLA loci. Further studies are needed, especially regarding the cut-off of MFI values that have clinical consequences on graft survival, and the impact of anti-DP antibodies, since mismatches are most frequent in this locus even for 10/10 matched unrelated donors.

\section{AUTHOR CONTRIBUTIONS}

SMZ wrote the manuscript. PL, JLT and SCZ commented on the manuscript at all stages of writing and edited it. All authors listed have made substantial, direct, and intellectual contribution to the work and approved it for publication.

components. Fukushima JMed Sci (2003) 49(1):45-54. doi:10.5387/ fms. 49.45

14. Karpinski M, Pochinco D, Dembinski I, Laidlaw W, Zacharias J, Nickerson P. Leukocyte reduction of red blood cell transfusions does not decrease allosensitization rates in potential kidney transplant candidates. J Am Soc Nephrol (2004) 15(3):818-24. doi:10.1097/01.ASN.0000115399.80913.B1

15. Mickelson EM, Petersdorf EW, Hansen JA. HLA matching and hematopoietic cell transplant outcome. Clin Transpl (2002):263-71.

16. Ottinger HD, Rebmann V, Pfeiffer KA, Beelen DW, Kremens B, Runde V, et al. Positive serum crossmatch as predictor for graft failure in HLAmismatched allogeneic blood stem cell transplantation. Transplantation (2002) 73(8):1280-5. doi:10.1097/00007890-200204270-00016

17. Yabe H, Morimoto T, Takakura H, Okuya M, Ikegaya R, Kato S, et al. Posttransplantation-emerging anti-HLA DQA1/DQB1 antibody possibly responsible for graft rejection after myeloablative-unrelated marrow grafting. Bone Marrow Transplant (2016) 51(4):601-3. doi:10.1038/bmt.2015.292

18. Kong Y, Chang Y-J, Wang Y-Z, Chen Y-H, Han W, Wang Y, et al. Association of an impaired bone marrow microenvironment with secondary poor graft function after allogeneic hematopoietic stem cell transplantation. Biol Blood Marrow Transplant (2013) 19(10):1465-73. doi:10.1016/j.bbmt.2013. 07.014

19. Klyuchnikov E, El-Cheikh J, Sputtek A, Lioznov M, Calmels B, Furst S, et al. CD34(+)-selected stem cell boost without further conditioning for poor graft function after allogeneic stem cell transplantation in patients with hematological malignancies. Biol Blood Marrow Transplant (2014) 20(3):382-6. doi:10.1016/j.bbmt.2013.11.034

20. Davies SM, Kollman C, Anasetti C, Antin JH, Gajewski J, Casper JT, et al. Engraftment and survival after unrelated-donor bone marrow transplantation: a report from the national marrow donor program. Blood (2000) 96(13):4096-102.

21. Rubinstein P, Carrier C, Scaradavou A, Kurtzberg J, Adamson J, Migliaccio AR, et al. Outcomes among 562 recipients of placental-blood transplants from unrelated donors. N Engl J Med (1998) 339(22):1565-77. doi:10.1056/ NEJM199811263392201

22. Laughlin MJ, Eapen M, Rubinstein P, Wagner JE, Zhang M-J, Champlin RE, et al. Outcomes after transplantation of cord blood or bone marrow from unrelated donors in adults with leukemia. N Engl J Med (2004) 351(22):2265-75. doi:10.1056/NEJMoa041276

23. Rocha V, Labopin M, Ruggeri A, Podestà M, Gallamini A, Bonifazi F, et al. Unrelated cord blood transplantation: outcomes after single-unit intrabone injection compared with double-unit intravenous injection in patients with hematological malignancies. Transplantation (2013) 95(10):1284-91. doi:10.1097/TP.0b013e318288ca4d

24. Atsuta Y, Suzuki R, Nagamura-Inoue T, Taniguchi S, Takahashi S, Kai S, et al. Disease-specific analyses of unrelated cord blood transplantation compared with unrelated bone marrow transplantation in adult patients with acute leukemia. Blood (2009) 113(8):1631-8. doi:10.1182/blood-2008-03-147041

25. Eapen M, Rocha V, Sanz G, Scaradavou A, Zhang M-J, Arcese W, et al. Effect of graft source on unrelated donor haemopoietic stem-cell transplantation 
in adults with acute leukaemia: a retrospective analysis. Lancet Oncol (2010) 11(7):653-60. doi:10.1016/S1470-2045(10)70127-3

26. Hickey MJ, Valenzuela NM, Reed EF. Alloantibody generation and effector function following sensitization to human leukocyte antigen. Front Immunol (2016) 7:30. doi:10.3389/fimmu.2016.00030

27. Xu H, Chilton PM, Tanner MK, Huang Y, Schanie CL, Dy-Liacco M, et al. Humoral immunity is the dominant barrier for allogeneic bone marrow engraftment in sensitized recipients. Blood (2006) 108(10):3611-9. doi:10.1182/blood-2006-04-017467

28. Taylor PA, Ehrhardt MJ, Roforth MM, Swedin JM, Panoskaltsis-Mortari A, Serody JS, et al. Preformed antibody, not primed T cells, is the initial and major barrier to bone marrow engraftment in allosensitized recipients. Blood (2007) 109(3):1307-15. doi:10.1182/blood-2006-05-022772

29. Loupy A, Lefaucheur C, Vernerey D, Prugger C, Duong van Huyen J-P, Mooney N, et al. Complement-binding anti-HLA antibodies and kidneyallograft survival. N Engl JMed (2013) 369(13):1215-26. doi:10.1056/ NEJMoa1302506

30. Sicard A, Amrouche L, Suberbielle C, Carmagnat M, Candon S, Thervet E, et al. Outcome of kidney transplantations performed with preformed donor-specific antibodies of unknown etiology. Am J Transplant (2014) 14(1):193-201. doi:10.1111/ajt.12512

31. Ciurea SO, Thall PF, Milton DR, Barnes TH, Kongtim P, Carmazzi Y, et al. Complement-binding donor-specific anti-HLA antibodies and risk of primary graft failure in hematopoietic stem cell transplantation. Biol Blood Marrow Transplant (2015) 21(8):1392-8. doi:10.1016/j.bbmt.2015.05.001

32. Falkenburg JH, Jansen J, van der Vaart-Duinkerken N, Veenhof WF, Blotkamp J, Goselink HM, et al. Polymorphic and monomorphic HLA-DR determinants on human hematopoietic progenitor cells. Blood (1984) 63(5):1125-32.

33. Busch FW, Langer M, Pawelec G, Ziegler A, Wernet P, Bühring HJ, et al. HLA-class II antigens on human hematopoietic progenitors. Blut (1987) 54(3):179-88. doi:10.1007/BF00320375

34. Spellman S, Bray R, Rosen-Bronson S, Haagenson M, Klein J, Flesch S, et al. The detection of donor-directed, HLA-specific alloantibodies in recipients of unrelated hematopoietic cell transplantation is predictive of graft failure. Blood (2010) 115(13):2704-8. doi:10.1182/blood-2009-09-244525

35. Shaw BE, Mayor NP, Russell NH, Apperley JF, Clark RE, Cornish J, et al. Diverging effects of HLA-DPB1 matching status on outcome following unrelated donor transplantation depending on disease stage and the degree of matching for other HLA alleles. Leukemia (2010) 24(1):58-65. doi:10.1038/ leu.2009.239

36. Ciurea SO, Thall PF, Wang X, Wang SA, Hu Y, Cano P, et al. Donor-specific anti-HLA Abs and graft failure in matched unrelated donor hematopoietic stem cell transplantation. Blood (2011) 118(22):5957-64. doi:10.1182/ blood-2011-06-362111

37. Cluzeau T, Lambert J, Raus N, Dessaux K, Absi L, Delbos F, et al. Risk factors and outcome of graft failure after HLA matched and mismatched unrelated donor hematopoietic stem cell transplantation: a study on behalf of SFGM-TC and SFHI. Bone Marrow Transplant (2016) 51(5):687-91. doi:10.1038/ bmt.2015.351

38. Ciurea SO, de Lima M, Cano P, Korbling M, Giralt S, Shpall EJ, et al. High risk of graft failure in patients with anti-HLA antibodies undergoing haploidentical stem-cell transplantation. Transplantation (2009) 88(8):1019-24. doi:10.1097/ TP.0b013e3181b9d710

39. Yoshihara S, Maruya E, Taniguchi K, Kaida K, Kato R, Inoue T, et al. Risk and prevention of graft failure in patients with preexisting donor-specific HLA antibodies undergoing unmanipulated haploidentical SCT. Bone Marrow Transplant (2012) 47(4):508-15. doi:10.1038/bmt.2011.131

40. Chang Y-J, Zhao X-Y, Xu L-P, Zhang X-H, Wang Y, Han W, et al. Donor-specific anti-human leukocyte antigen antibodies were associated with primary graft failure after unmanipulated haploidentical blood and marrow transplantation: a prospective study with randomly assigned training and validation sets. J Hematol Oncol (2015) 8:84. doi:10.1186/s13045-015-0182-9

41. Takanashi M, Atsuta Y, Fujiwara K, Kodo H, Kai S, Sato H, et al. The impact of anti-HLA antibodies on unrelated cord blood transplantations. Blood (2010) 116(15):2839-46. doi:10.1182/blood-2009-10-249219
42. Cutler C, Kim HT, Sun L, Sese D, Glotzbecker B, Armand P, et al. Donor-specific anti-HLA antibodies predict outcome in double umbilical cord blood transplantation. Blood (2011) 118(25):6691-7. doi:10.1182/blood2011-05-355263

43. Ruggeri A, Rocha V, Masson E, Labopin M, Cunha R, Absi L, et al. Impact of donor-specific anti-HLA antibodies on graft failure and survival after reduced intensity conditioning-unrelated cord blood transplantation: a Eurocord, Société Francophone d'Histocompatibilité et d'Immunogénétique (SFHI) and Société Française de Greffe de Moelle et de Thérapie Cellulaire (SFGM-TC) analysis. Haematologica (2013) 98(7):1154-60. doi:10.3324/ haematol.2012.077685

44. Yamamoto H, Uchida N, Matsuno N, Ota H, Kageyama K, Wada S, et al. Anti-HLA antibodies other than against HLA-A, -B, -DRB1 adversely affect engraftment and nonrelapse mortality in HLA-mismatched single cord blood transplantation: possible implications of unrecognized donor-specific antibodies. Biol Blood Marrow Transplant (2014) 20(10):1634-40. doi:10.1016/j. bbmt.2014.06.024

45. Yell M, Muth BL, Kaufman DB, Djamali A, Ellis TM. Clq binding activity of de novo donor-specific HLA antibodies in renal transplant recipients with and without antibody-mediated rejection. Transplantation (2015) 99(6):1151-5. doi:10.1097/TP.0000000000000699

46. Schaub S, Hönger G, Koller MT, Liwski R, Amico P. Determinants of C1q binding in the single antigen bead assay. Transplantation (2014) 98(4):387-93. doi:10.1097/TP.0000000000000203

47. Guidicelli G, Guerville F, Lepreux S, Wiebe C, Thaunat O, Dubois V, et al. Non-complement-binding de novo donor-specific anti-HLA antibodies and kidney allograft survival. J Am Soc Nephrol (2016) 27(2):615-25. doi:10.1681/ ASN.2014040326

48. Loiseau P, Amokhrane K, Visentin J, Kheav V-D, Caillat-Zucman S, Taupin J-L. Use of single-antigen flow beads assays to assess anti-HLA donor-specific antibody strength. Biol Blood Marrow Transplant (2016) 22(2):394-5. doi:10.1016/j.bbmt.2015.11.006

49. Lapierre V, Aupérin A, Tayebi H, Chabod J, Saas P, Michalet M, et al. Increased presence of anti-HLA antibodies early after allogeneic granulocyte colony-stimulating factor-mobilized peripheral blood hematopoietic stem cell transplantation compared with bone marrow transplantation. Blood (2002) 100(4):1484-9. doi:10.1182/blood-2001-11-0039

50. Taniguchi K, Yoshihara S, Maruya E, Ikegame K, Kaida K, Hayashi K, et al. Donor-derived HLA antibody production in patients undergoing SCT from HLA antibody-positive donors. Bone Marrow Transplant (2012) 47(10): 1338-42. doi:10.1038/bmt.2012.28

51. Hatakeyama N, Hori T, Yamamoto M, Inazawa N, Iesato K, Miyazaki T, et al. Platelet transfusion refractoriness attributable to HLA antibodies produced by donor-derived cells after allogeneic bone marrow transplantation from one HLA-antigen-mismatched mother. Pediatr Transplant (2011) 15(8):E177-82. doi:10.1111/j.1399-3046.2010.01365.x

52. Delbos F, Barhoumi W, Cabanne L, Beckerich F, Robin C, Redjoul R, et al. Donor immunization against human leukocyte class II antigens is a risk factor for graft-versus-host disease. Biol Blood Marrow Transplant (2016) 22(2):292-9. doi:10.1016/j.bbmt.2015.09.027

53. Narimatsu H, Wake A, Miura Y, Tanaka H, Matsumura T, Takagi S, et al. Successful engraftment in crossmatch-positive HLA-mismatched peripheral blood stem cell transplantation after depletion of antidonor cytotoxic HLA antibodies with rituximab and donor platelet infusion. Bone Marrow Transplant (2005) 36(6):555-6. doi:10.1038/sj.bmt.1705070

Conflict of Interest Statement: The authors declare that the research was conducted in the absence of any commercial or financial relationships that could be construed as a potential conflict of interest.

Copyright () 2016 Morin-Zorman, Loiseau, Taupin and Caillat-Zucman. This is an open-access article distributed under the terms of the Creative Commons Attribution License (CC BY). The use, distribution or reproduction in other forums is permitted, provided the original author(s) or licensor are credited and that the original publication in this journal is cited, in accordance with accepted academic practice. No use, distribution or reproduction is permitted which does not comply with these terms. 